\title{
МИКРОБИОЦЕНОЗ НИЖНИХ ДЫХАТЕЛЬНЫХ ПУТЕЙ ПРИ ПНЕВМОНИИ, АССОЦИИРОВАННОЙ С SARS-COV-2
}

Л. В. Катаева, Т. Ф. Степанова, К. Б. Степанова, И. В. Бакштановская, О. В. Посоюзных, В. В. Ташланова, Н. Ф. Карпухина, О. Н. Колотова, Ю. Н. Калашникова, А. А. Вакарина

ФБУН «Тюменский научно-исследовательский институт краевой инфекционной патологии» Роспотребнадзора, г. Тюмень

Представлены результаты исследования микробного пейзажа содержимого нижних дыхательных путей при внебольничной пневмонии, ассоциированной с COVID-19. Показано, что в структуре бактерий выделенных от пациентов с диагнозом внебольничная пневмония превалируют грамположительные кокки, преимущественно бактерии рода Streptococcus. По частоте обнаружения бактерий семейства Enterobacteriaceae и неферментирующих грамотрицательных бактерий в сравниваемых группах (SARS-COV-2 «обнаружен» / «не обнаружен») статистически значимых различий не отмечено.

Ключевые слова: внебольничная пневмония, виды бактерий, мокрота, промывные воды бронхов, бронхоальвеолярный лаваж.

Пандемия коронавирусной болезни 2019 года (COVID-19) по праву считается главной чрезвычайной ситуацией в области здравоохранения за столетие. У значительной части пациентов развивается пневмония, требующая госпитализации или прогрессирования до манифестации респираторных осложнений [8]. Данные литературы свидетельствуют о том, что этиология внебольничной пневмонии установлена в 88,5 \% случаев методом ПЦР. Ведущими возбудителями указаны Streptococcus pneumoniae и Haemophilus influenzae, которые были выявлены в 86,3\% и 41,2\% случаев соответственно. В число актуальных возбудителей внебольничной пневмонии вошли Mycoplasma pneumoniae (23,6\%), Adenovirus (14,9\%). Chlamydophila pneumoniae обнаруживается значительно реже $(6,7 \%)$. Характерной особенностью внебольничных пневмоний на современном этапе является наличие большого числа ассоциаций микроорганизмов, как бактерий, так и вирусов [1].

Несмотря на то, что в популяции 1-6\% населения являются носителями Klebsiella pneumoniae, локализованной в носоглотке и 5 - 38\% - в кишечнике, у госпитализированных пациентов носительство $K$. pneuтоniae намного выше, чем в популяции, носителями возбудителя являлись $23 \%$ госпитализированных пациентов [9]. В целом, информация по возбудителям бактериальных пневмоний указывает на полимикробную этиологию, и данные очень разнятся [6]. Чаще указываются представители группы 
Enterobacteriaceae (Klebsiella pneumoniae), являющиеся маркером прогностически неблагоприятного течения процесса в легких [3].

Целью работы явилась сравнительная характеристика результатов микробиологического исследования содержимого нижних дыхательных путей при внебольничной пневмонии бактериального генеза с COVID-19 ассоциированной пневмонией.

Материалы и методы. Материалом для исследования служили мокрота, промывные воды бронхов, бронхоальвеолярный лаваж 199 пациентов, находящихся на стационарном лечении с подтвержденным диагнозом «внебольничная пневмония» различной степени тяжести.

Отбор и транспортировка биологического материала для лабораторных исследований проводился в соответствии с требованиями законодательства РФ в отношении возбудителей инфекционных заболеваний человека I-II групп патогенности [7].

Посев клинического материала и выделение штаммов осуществлялось общепринятыми методами в соответствии с Приказом №535 «Об унификации микробиологических (бактериологических) методов исследования, применяемых в клинико-диагностических лабораториях лечебно-профилактических учреждений» [5]. Идентификация выделенных штаммов бактерий осуществлялась по прямому белковому профилированию с помощью времяпролетной масс-спектрометрии с программным обеспечением Maldi BioTyper 3,0. Уровень достоверности выше 2,0 свидетельствовал о точной видовой идентификации. Для каждого исследованного штамма бактерий приводилась ссылка на NCBI (National Center for Biotechnology Information).

Чувствительность к антимикробным препаратам определяли дискодиффузионным методом, результаты оценивали в соответствии с действующими нормативными документами $[2,4]$.

Статистическую обработку материала по видовому составу и биологическим свойствам осуществляли в компьютерной оболочке Windows с помощью процессора электронных таблиц Microsoft Office Excel 2003 с вычислением показателей: средней арифметической (M), средней ошибки средней величины (m), коэффициента корреляции (r). Полученные данные были подвергнуты статистической обработке параметрическим методом с применением t-критерия Стьюдента.

\section{Результаты и обсуждение.}

Наличие SARS-CoV-2 лабораторно подтверждено у 95 пациентов с диагнозом внебольничная пневмония, что составило 48 \%. В сравниваемых группах (SARS-COV-2 «обнаружен» / «не обнаружен») в равной степени в содержимом нижних дыхательных путей роста бактериальной флоры не зарегистрировано в 11,6 \% и 10,6 \% проб соответственно.

Показано, что в структуре бактерий, выделенных от пациентов обеих групп (таблица 1) превалируют грамположительные кокки, в частности, преимущественно бактерии рода Streptococcus, относящиеся к сапрофитной 
микрофлоре слизистой верхних дыхательных путей. Из условно-патогенных стрептококков был изолирован Streptococcus pneumoniae, причем только у двух пациентов с лабораторно подтвержденным COVID-19.

Таблица 1. Этиологическая структура внебольничной пневмонии

\begin{tabular}{|c|c|c|c|c|}
\hline \multirow{3}{*}{ Возбудитель } & \multicolumn{4}{|c|}{ Частота выявления (\%) } \\
\hline & \multicolumn{2}{|c|}{$\begin{array}{c}\text { SARS-COV-2 } \\
\text { обнаружен }\end{array}$} & \multicolumn{2}{|c|}{$\begin{array}{l}\text { SARS-COV-2 } \\
\text { не обнаружен }\end{array}$} \\
\hline & абс. число & $\%$ & абс. число & $\%$ \\
\hline \multicolumn{5}{|c|}{ Бактерии семейства Enterobacteriaceae } \\
\hline Klebsiella pneumoniae & 8 & 8.42 & 25 & 24.0 \\
\hline Klebsiella variicola & 1 & 1.05 & - & - \\
\hline Escherichia coli & 5 & 5.3 & 6 & 5.8 \\
\hline Serratia marcescens & 1 & 1.05 & - & - \\
\hline Pantoea agglomerans & 1 & 1.05 & - & - \\
\hline Raoultella terrigena & 1 & 1.05 & - & - \\
\hline Raoultella ornithinolytica & 1 & 1.05 & - & - \\
\hline Всего & 18 & 21.2 & 31 & 30.7 \\
\hline \multicolumn{5}{|c|}{ Грамотрицательные бактерии, в том числе неферментирующие } \\
\hline Acinetobacter baumannii & 7 & 7.37 & 19 & 18.3 \\
\hline Pseudomonas aeruginosa & 2 & 2.1 & 6 & 5.8 \\
\hline Haemophilus parainfluenzae & 2 & 2.1 & 2 & 1.9 \\
\hline Stenotrachomonas malthophilia & - & - & 1 & 0.96 \\
\hline Всего & 11 & 12.9 & 28 & 27.7 \\
\hline \multicolumn{5}{|c|}{ Грамположительные бактерии } \\
\hline Staphylococcus haemolyticus & 4 & 4.21 & - & - \\
\hline Staphylococcus aureus & 2 & 2.1 & 5 & 4.8 \\
\hline Streptococcus pneumoniae & 2 & 2.1 & - & - \\
\hline Streptococcus spp. & 44 & 46.3 & 35 & 33.6 \\
\hline Enterococcus faecium & 4 & 4.21 & 2 & 1.9 \\
\hline Всего & 56 & 65.9 & 42 & 41.6 \\
\hline \multicolumn{5}{|c|}{ Грибы } \\
\hline Candida spp. & 49 & 51.6 & 50 & 48.08 \\
\hline
\end{tabular}

По частоте обнаружения бактерий семейства Enterobacteriaceae и неферментирующих грамотрицательных бактерий в сравниваемых группах статистически значимых различий не отмечено. В группе пациентов с подтвержденным обнаружением COVID-19 спектр бактерий семейства Enterobacteriaceae шире, встречаются бактерии родов Serratia, Pantoea, Raoultella. Следует отметить, что бактерии Klebsiella pneumoniae чаще идентифицировались в группе пациентов с диагнозом пневмония, лабораторного подтверждения обнаружения COVID-19 у которых не 
зарегистрировано. В этой группе пациентов также чаще были изолированы неферментирующие грамотрицательные бактерии - Acinetobacter baumannii и Pseudomonas aeruginosa. Возможно, эти тенденции связаны с различными подходами в антибиотикотерапии пневмоний с подтверждённым COVID-19.

Грибы рода Candida выделялись из содержимого верхних дыхательных путей в среднем у половины пациентов с диагнозом пневмония в обеих группах, чаще всего идентифицировались C. albicans (80.0\%). Кроме того, были изолированы виды - C. kefir, C. glabrata, C. dubliniensis, C. tropicalis, C. krusei.

Таким образом, результаты исследования микробного пейзажа содержимого нижних дыхательных путей пациентов с диагнозом внебольничная пневмония, ассоциированная с COVID-19, и при не подтвержденном лабораторно наличии SARS-COV-2 свидетельствуют о том, что в структуре бактерий превалируют грамположительные кокки, преимущественно бактерии рода Streptococcus. По частоте обнаружения бактерий семейства Enterobacteriaceae и неферментирующих грамотрицательных бактерий в сравниваемых группах (SARS-COV-2 «обнаружен» / «не обнаружен») статистически значимых различий не отмечено. Среди бактерий семейства Enterobacteriaceae чаще идентифицировались Klebsiella pneumoniae, в группе грамотрицательных неферментирующих бактерий - Acinetobacter baumannii.

\section{Литература}

1. Бруснигина Н. Ф., Мазепа В. Н., Самохина Л. П., Черневская О.М., Орлова К. А., Сперанская Е. В., Скобло Л. Е., Кленина Н. Н., Барышева Н.Н. Этиологическая структура внебольничной пневмонии // Медицинский альманах. - 2009. - №2(7). - С. 118-121.

2. Клинические рекомендации «Определение чувствительности микроорганизмов к антимикробным препаратам». 2018-03.

3. Молчанова О.В., Хамидулина А.И., Щенников Э.Л., Иванова О.А., Шмыленко В.А. Этиологическая структура внебольничной пневмонии у больных с факторами риска неблагоприятного течения заболевания // Дальневосточный журнал инфекционной патологии. - 2008. - № 12 (12). - С. 59-62.

4. МУК 4.2.1890-04 «Определение чувствительности микроорганизмов к антибактериальным препаратам».

5. Приказ Министерства здравоохранения СССР от 22.04.1985 № 535 «Об унификации бактериологических (микробиологических) методов исследования, применяемых в клинико-диагностических лабораториях лечебно-профилактических учреждений».

6. Розанова С.М., Шилова В.П., Перевалова Е.Ю., Шевелева Л.В., Кругова К.В., Беикин Я.Б., Руднов В.А., Багин В.А. Микробиологическая 
диагностика вентилятор-ассоциированной пневмонии: практический опыт работы // Уральский медицинский журнал. - 2008. - №13(53). - С. 64-67. 7. СП 3.1.3597-20 Профилактика новой коронавирусной инфекции (COVID-19).

8. Стулова М.В., Кудряшева И.А., Полунина О.С., Черенова Л.П., Аршба T.Е., Лисина О.А., Казакова Е.А. Сравнительный клинико-лабораторный анализ covid-19 ассоциированной пневмонии с внебольничной пневмонией бактериальной этиологии // Современные проблемы науки и образования. 2020. - № 3. - С. 134.

9. Фесенко О.В., Швайко С.Н. Пневмонии, вызванные Klebsiella pneumoniae (фридлендеровские пневмонии) // Практическая пульмонология. 2019. - № 1. - C. 22-31. 